\title{
MEXITERPES SABINUS, NEW GENUS AND NEW SPECIES, A MEXICAN TROGLOBITE (DIPLOPODA: TRICHOPETALIDAE)*
}

\author{
By Nell B. Causey
}

\section{University of Arkansas, Fayetteville, Arkansas}

This troglobitic milliped is of unusual interest because it is the type of a new genus and the first Mexican record of the family Trichopetalidae, which previously has been known from Nova Scotia to Louisiana, Oklahoma, and Colorado. If the genus has undergone speciation as related genera have, then additional species and subspecies will be found in other Mexican caves. Other millipeds from Mexican caves have been described by R. V. Chamberlin ( 1942).

I am indebted to the members of the Texas Speleological Survey for the specimen from which this species was described.

\section{Genus Mexiterpes, new}

Type-species: $M$. sabinus, n. sp. Monobasic.

Diagnosis. Depigmented, eyeless, medium-sized trichopetalids of 30 body segments that are nearest $S$ coterpes. Characterized by the gonopods and by the unmodified condition of all pregonopodal legs. Coxa of anterior gonopods bears one short branch on its distal margin; telopodite is thick and short as in Scoterpes, but is more complex, seems to lack a plumose branch, and has a short, ectal, setose branch. Posterior gonopods are short, slender, and consist of 4 articles; article I is coalesced with its homologue in midline, and there is no partition between them; all other articles are separated by partitions; a gland opening is on article I at base of telopodite; article 2 is elongated as is usual in the family; combined length of articles 3 and 4 , which are not inflated, is a little less than length of article 2.

\section{Mexiterpes sabinus, new species}

Figures I-3

Type locality. Mexico: San Luis Potosí: Sótano del Arroyo, which is near village of Los Sabinos and 8 miles north of Valles; I specimen was collected on silt in Big Room 3000 feet from entrance after intensive search 24 Nov. 1962 by James R. Reddell.

Deposition. Male holotype is in Museum of Comparative Zoology. Posterior gonopods are mounted on a slide; anterior gonopods are in a microvial.

*,Manuscript received by the editor May 8, 1963. 

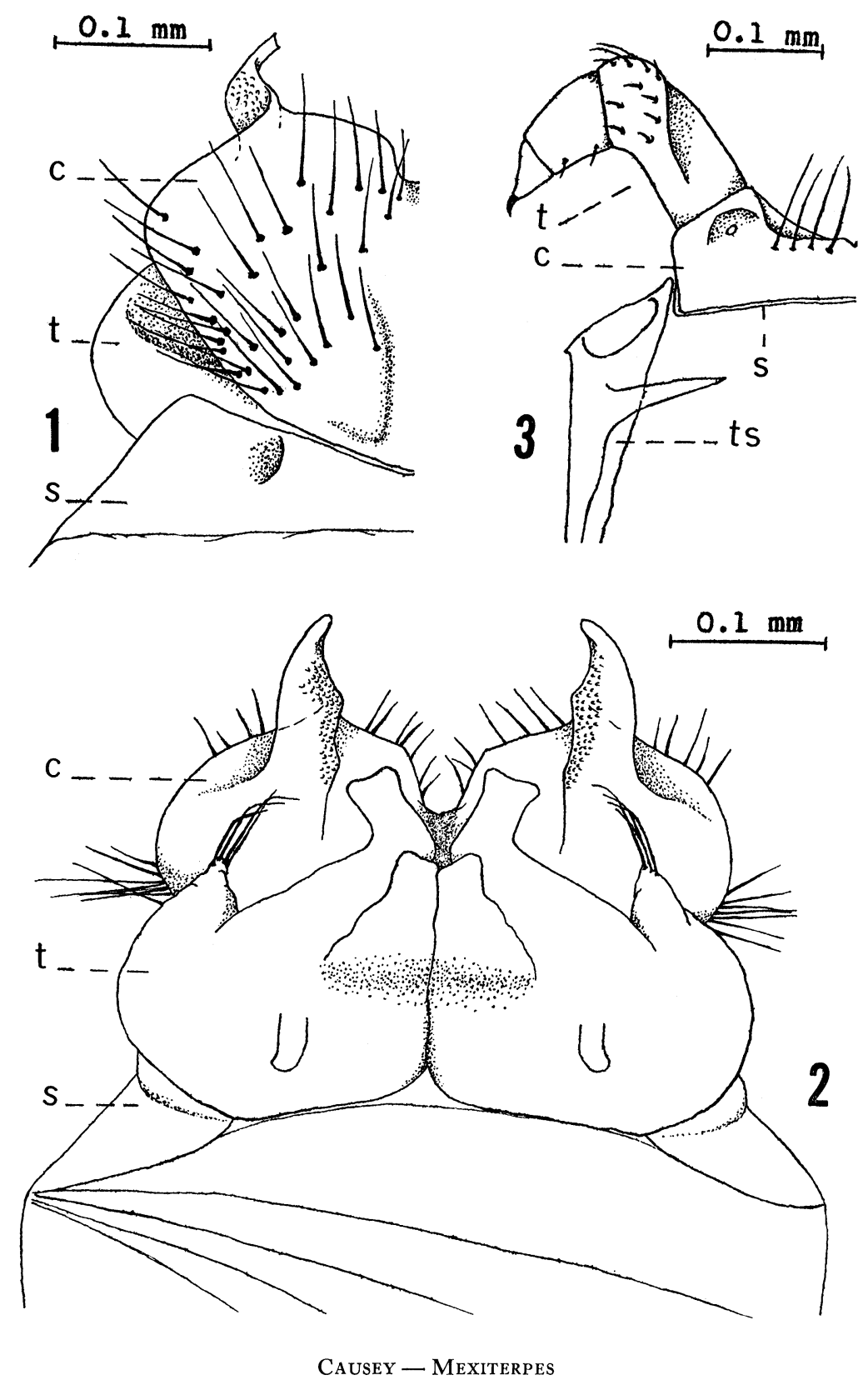
Description of male holotype. Length is about $9 \mathrm{~mm}$.; width is $0.9 \mathrm{~mm}$. Body is white except for black gut contents. Length of antennae is $\mathrm{I} .2 \mathrm{~mm}$.; ratio of length of articles $\mathrm{I}-7$ is $2: 4: 5.6: 6: 8: 3: 2$. Segmental setae are relatively coarse, attenuated, slightly curved, and in slightly oblique rows on ectal one-fourth of metatergites; their length is from $1 / 2$ to $3 / 4$ the body width; no mucus droplets are on setae. Shoulders are prominent, with ectocephalic margin rounded and outermost seta on ectocaudal angle. No pregonopodal legs are modified; no tarsal setae are capitate. Legpairs IO and I I are unmodified except for the usual gland opening on coxae. Somatic characters that are not mentioned are as in species of Scoterpes and $\boldsymbol{Z} \boldsymbol{y}$ gonopus.

Figure $\mathrm{I}$ is an anterior view of right half of anterior gonopods and their sternum; no distinct partition is in midline of coxal region, which juts forward at base and is coarsely setose. Figure 2 is a caudal view of anterior gonopods; telopodite is wide, thick, coalesced to its homologue, and has 4 short branches on caudal surface; ectal branch bears 4 stout, curved setae; if there is a plumose branch, it is between coxa and telopodite; opening of sperm canal, which is probably on anterior surface of telopodite, was not observed. Figure 3 is an anterior view of right half of posterior gonopods; sternum is thin; tracheal pouches and spiracles are large; syncoxa is thick, lacks a partition in midline, has Io stout setae on ventral margin, and has the usual gland opening at base of telopodite; terminal claw is minute.

Sternum of anterior gonopods will be described when more material can be obtained.

\section{Family Trichopetalidae Verhoeff 1932}

Species of the Trichopetalidae have either 28 or 30 body segments, are either pigmented or depigmented, and have conspicuous segmental setae. Ocelli are absent in troglobitic species; in epigean species, ocelli are arranged in a single series, in irregular lunate patches, or in triangular patches of up to I 5. Male: Legpairs Io and I I have a gland opening on the coxae. Anterior gonopods are coalesced; coxal region is large, has one or more branches on the distal margin, and is distinctly divided from the telopodite, which is behind it and variously developed. Posterior gonopods consist of from 3 to 5 articles either

\section{Explanation of Plate 27}

Figs. 1-3. Mexiterpes sabinus, n. gen. and n. sp. 1, Anterior view of right anterior gonopod. 2. Posterior view of anterior gonopods. 3. Anterior view of right posterior gonopod. c, coxa; t, telonodite: $t$. tracheal sac: s. sternum. 
with or without a terminal claw; a partition between prefemur and femur is always present; partitions between other articles are either present or absent; coxa has a gland opening, which may be on a simple, rounded lobe; prefemur is elongated and more or less vertical; femur is usually swollen.

Species of the Conotylidae differ from the Trichopetalidae in that all have 30 body segments, all have ocelli, they tend to be larger, they are often darkly pigmented, segmental setae are sometimes shorter, and the coxae of legpair I I of the male lack a gland opening. Anterior gonopods are not coalesced, are simpler, do not have the coxa and telopodite distinctly divided, and frequently are smaller than the coxal endites of the posterior gonopods. Posterior gonopods consist of 3 articles, lack a terminal claw, and there are partitions between all of the articles.

Troglobitic species of the Trichopetalidae outnumber the epigean species, possibly because of more zealous collecting in caves. Flagellopetalum is known by one collection of the type species in Illinois. Scoterpes, entirely troglobitic, is represented by many species and subspecies in Missouri, Kentucky, Tennessee, Georgia and Alabama. 'I'richopetalum, the most widely distributed genus of the family, is represented by five species (Chamberlin and Hoffman, 1958) from Nova Scotia to Oklahoma. Immature specimens from Louisiana and Colorado have been tentatively assigned to this genus. Trigenotyla is represented by two species in Arkansas and Oklahoma. Craspedosoma flavidum Bollman, which I have not seen, may go into this genus. Tynopus is known by a single collection of the type species from North Carolina; I have not examined it; the number of body segments is unknown. Zygonopus, entirely troglobitic, is in Virginia and West Virginia; the four species that I formerly assigned to it (Causey, 1960) are two species, of which one is composed of three subspecies. The following key to the genera emphasizes the ocelli too much and the gonopod structure too little.

\section{KEY TO THE GENERA OF THE FAMILY TRICHOPETALIDAE BASED MAINLY ON THE MALE}

I. About 8 ocelli are arranged in a bent series; length is about $4 \mathrm{~mm}$. Tynopus Chamberlin Ocelli are either otherwise or are absent; length is up to 15 $\mathrm{mm}$.

2. 28 body segments; with ocelli 
3. About 5 ocelli are in a single curved series; body is lightly pigmented Flagellopetalum Causey

Ocelli are in 2 or 3 irregular series; body is depigmented.

Trichopetalum Harger

4. I4 or 15 ocelli are in a triangular patch; body is either pigmented or depigmented; prefemur of posterior gonopods is prolonged well beyond its articulation with the smaller femur

Trigenotyla Causey

No ocelli; body is depigmented; prefemur of posterior gonopods is not prolonged beyond its articulation with femur 5

5. Legpair 7 of male is greatly enlarged .............. Zygonopus Ryder

Legpair 7 of male is enlarged either slightly or not at all ........... 6

6. Legpairs 3 through 7 of male have no special modification; a partition is between coxa and prefemur of posterior gonopods

Mexiterpes, new genus

One or more of legpairs 3 through 7 of male are modified; no partition is between coxa and prefemur of posterior gonopods

Scoterpes Cope

\section{Literature Cited}

Causey, Nell B.

1960. The troglobitic milliped genus Zygonopus (Chordeumida, Conotylidae, Trichopetalinae). Jour. New York Ent. Soc., $68: 69-80$, figs. 1-11.

Chamberlin, R. V.

1942. On centipeds and millipeds from Mexican caves. Bull. Univ. Utah, biol. ser., $7(2): 1-19,2$ pls.

Chamberlin, R. V., and Richard L. HoFfman

1958. Checklist of the millipeds of North America. U.S. Nat. Mus. Bull. 212, pp. 1-236. 

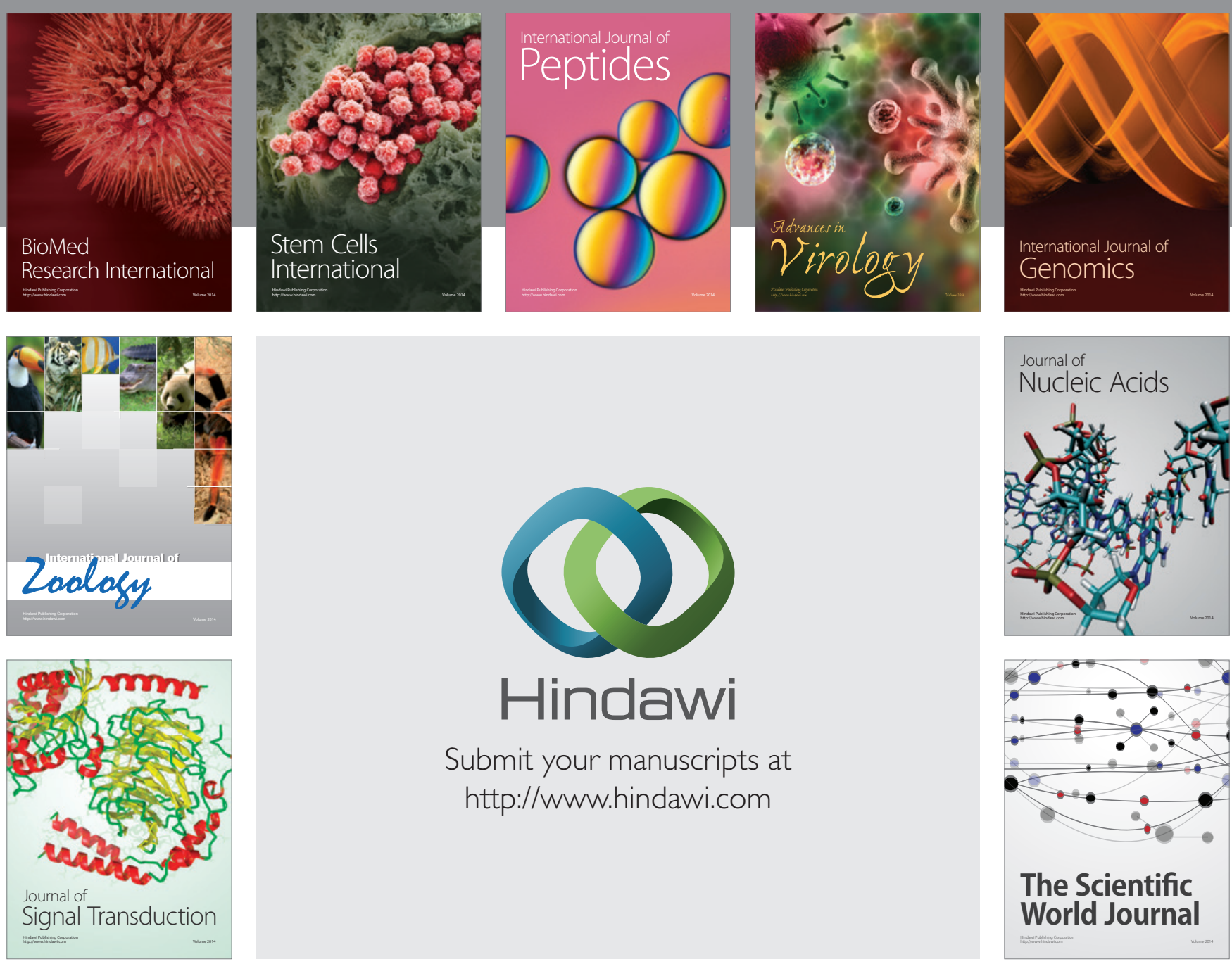

Submit your manuscripts at

http://www.hindawi.com
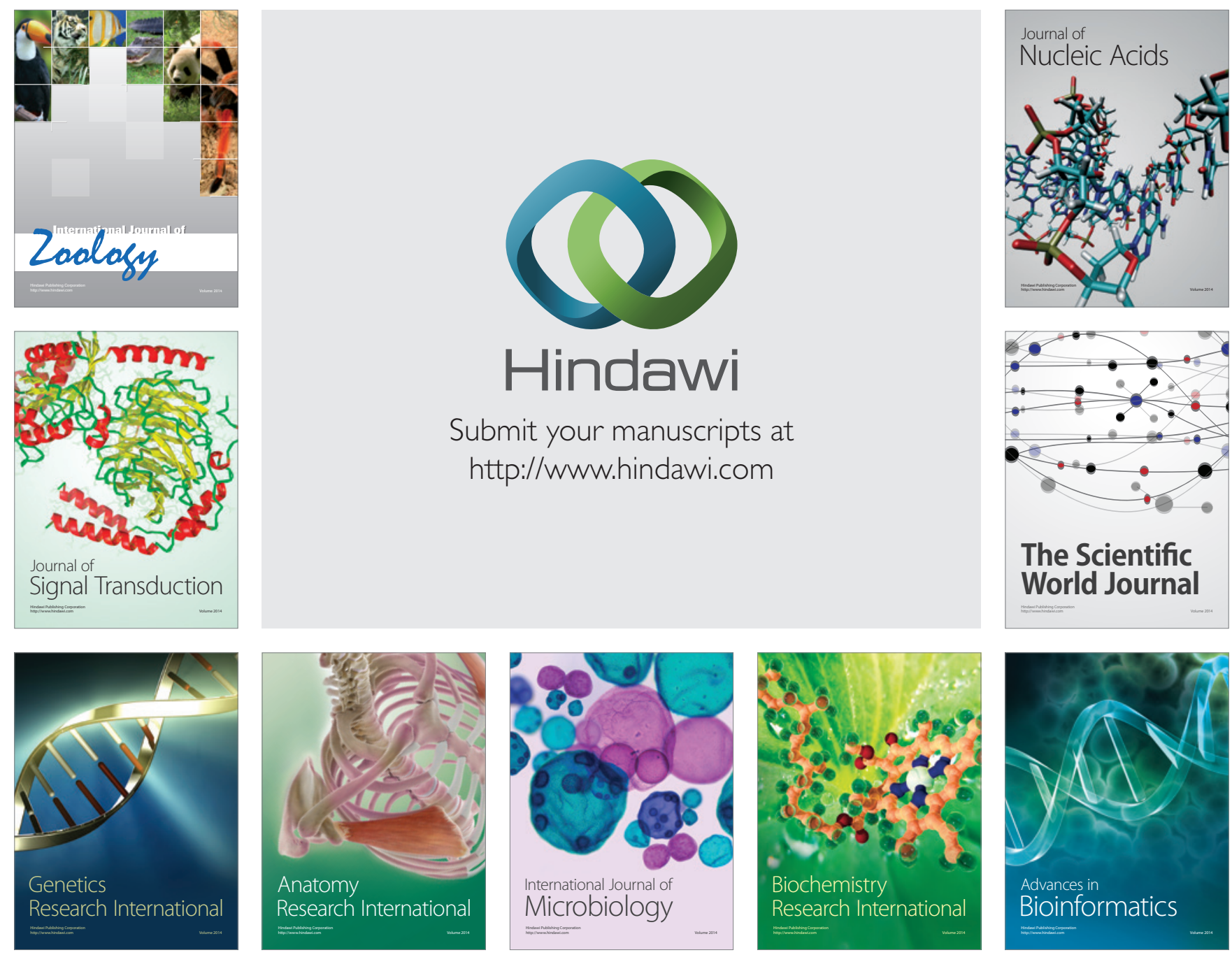

The Scientific World Journal
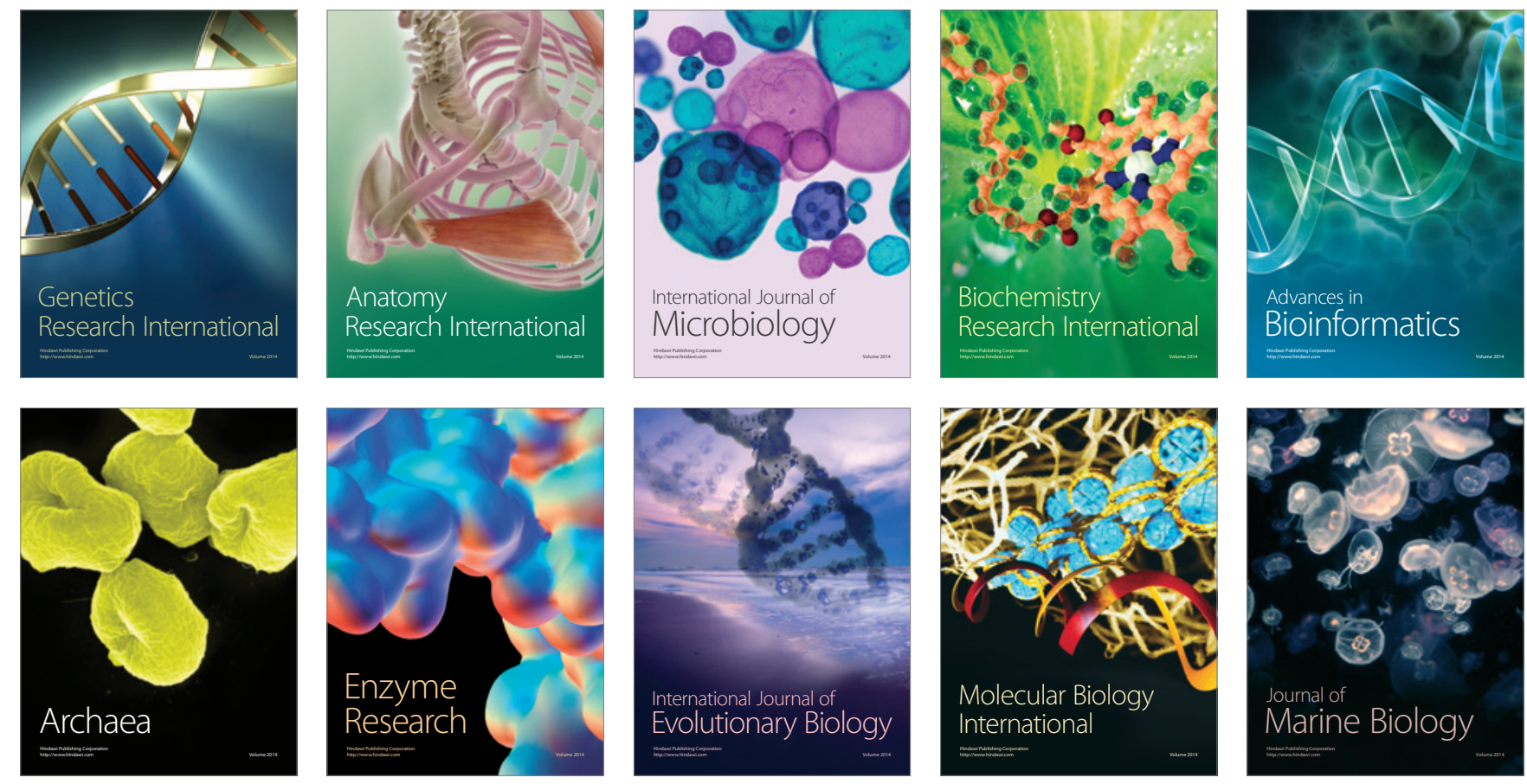